\title{
Carbon-based catalysts: Opening new scenario to develop next-generation nano-engineered catalytic materials
}

\author{
Claudio Ampelli, Siglinda Perathoner*, Gabriele Centi \\ University of Messina, INSTM/CASPE and ERIC aisbl, Italy
}

\begin{abstract}
This essay analyses some of the recent development in nanocarbons (carbon materials having a defined and controlled nano-scale dimension and functional properties which strongly depend on their nano-scale features and architecture), with reference to their use as advanced catalytic materials. It is remarked how their features open new possibilities for catalysis and that they represent a new class of catalytic materials. Although carbon is used from long time in catalysis as support and electrocatalytic applications, nanocarbons offer unconventional ways for their utilization and to address some of the new challenges deriving from moving to a more sustainable future. This essay comments how nanocarbons are a key element to develop next-generation catalytic materials, but remarking that this goal requires overcoming some of the actual limits in current research. Some aspects are discussed to give a glimpse on new directions and needs for R\&D to progress in this direction.

Keywords: Nano-carbon; Catalysis on carbon; Nanostructured carbonbased material; Carbon hierarchy; Nano-engineering of the carbon materials

Received 12 May 2014. Published 20 June 2014.

(C) 2014, Dalian Institute of Chemical Physics, Chinese Academy of Sciences. Published by Elsevier B.V. All rights reserved.
\end{abstract}

\section{Introduction}

Carbon is an old and new catalytic material [1-5]. Active carbons (AC) are used commercially in many catalytic formulations, particularly for hydrogenation catalysts, for the excellent properties of dispersion of metal particles (particularly based on noble metals) and absence (or limited) presence of sites, which may catalyse side reactions [6-8]. The different adsorption properties of carbon materials with respect to other type of supports, metal oxides for example, are another relevant element determining they large industrial use, particularly in selective hydrogenation reactions. There are many attracting properties in ACs:
- The high surface area, together with the possibility of tuning the porosity;

- The robustness and chemical inertness, apart in high-temperature reactions in the presence of oxygen;

- The flexible tuning of the surface properties, by changing for example the graphitic character (which is related to both electronic and heat conductivity) or the presence of surface groups induced by post- or pre-treatment, which allow to change various properties, between which the degree of hydro-philicity or -phobicity and the interaction with the supported catalytic nanoparticle;

- The low cost of production, between the cheaper of catalytic support materials.

However, carbon can be considered also as a new catalytic material. A large range of new nanocarbon materials have been recently developed recently [1-5,9-18], from the more known graphene, carbon nanotubes (CNTs) and fullerene (and their derivatives) to a large range of other type of sometime fancy nanostructures: nano-fibers, -coils, -diamond, -horns, -onion, etc. Here the term nanocarbon [1] indicates carbon materials having from zero- to tri-dimensional character, but characterized from an ordered structure at nano-scale dimension and from functional properties significantly depending on nano-scale characteristics $[19,20]$. These materials are specifically synthetized, while AC is mainly deriving from natural sources, although a series of treatments are necessary to obtain the necessary characteristics.

Nanocarbon (or alternatively nano-structured carbon) definition includes various types of carbon-based nanomaterials, from zero-dimensional such as carbon dots (we may classify here also fullerenes) to tri-dimensional ordered mesoporous carbon materials. We include in these definitions also carbon nano-composites with metal ions, metal-oxide, metals and quantum dots used in various applications as advanced elec-

\footnotetext{
*Corresponding author. Tel: +39-90-6765609; Fax: +39-90-391518; E-mail: perathon@unime.it This work was supported by MIUR/Italy (PRIN10-11 Project Mechanisms of $\mathrm{CO}_{2}$ Activation). 
trodes for energy conversion and storage, as well as other applications such as catalysis. These carbon/inorganic nano-hybrids are at the frontier of research for the development of advanced devices for sustainable energy, including artificial leaves [3,18,21-29]. Of growing interest, also the area of nanocarbon-nanocarbon hybrids, for example functionalized fullerenes linked to CNTs, in order to develop multifunctional superstructures, of particular relevance for example in the field of devices for solar light conversion or sensors [30-33].

\section{Outlook and economic perspectives}

Nanocarbons can be considered between the first nanotech materials with significant commercial use and mass-production, although the closing of production of some large manufacturers evidences how this field needs to establish on more solid bases. Bayer stopped to produce CNTs-commercial name Baytubes. Several other companies are facing growing difficulties and they are reshaping the market addressed; Nanocyl, for example, is moving to the specialized area of CNT-based coatings for naval applications. The research "excitement" about some of the classes of nanocarbons (graphene, in particular) has to be view from a longer term and correct industrial perspective. Even if discovered more than twenty years ago, CNTs still find problems in large-scale applications, although their cost of production decreased of two-three orders of magnitude. Thus, cost was not the only aspect determining their industrial use, as often indicated. The global CNTs industry is one of the largest in the area of nanotech materials, with about 700 million US\$ in 2010 (over $90 \%$ of which related to multi-walled carbon nanotubes-MWCNTs; production capacity was about 2500 metric tons [34]), but can be considered still small with respect to market for chemicals and materials. The outlooks are of expansion to more specialized uses, from electronic industry to that of materials for energy storage devices and photovoltaic cells [34], rather than to traditional area of plastics and composites, which still cover about $70 \%$ of the market.

This has clearly consequences on the use of CNTs in catalysis, because this market (in term of cost value of the product) is closer to commodities than to that of specialized products. We suggest that the scenario of evolution of the market in the future will seen the use of nanocarbon materials more oriented to high-tech applications rather than to large-scale applications (plastics and composite), the opposite of what supposed few years ago. In fact, the cost of processing these nanocarbons (for CNTs it is not only the cost of production, but of further treatment to realize an effective dispersion within the polymeric mass) still is not favourable (in terms of cost-effectiveness) with respect to alternatives. $R \& D$ will be thus more oriented to the preparation of specific nanocarbon materials for dedicated high-value productions rather than for large-scale productions. Thus, the decreasing trend observed in prices for CNTs will be probably inverted, driving to higher costs all the field of nanocarbon materials.

This will impact the use of nanocarbons in the preparation of novel catalysts. We have to remark that still no commercial catalysts are based on nanocarbons, if not for minor niche ap- plications. Although many papers claim the superior performances of nanocarbon-based catalysts, in general it was not proven the effective superior performances with respect to state-of-the-art (commercial) catalysts. The comparison is often not made with the appropriate benchmark catalysts and/or right experimental conditions (for example, high conversion). Even when comparison reveals better properties (which necessarily are not of reactivity only, they may allow reduced mass transfer limitation or better heat transfer, for example), the cost-effectiveness has to be considered. Although it is often not easy to estimate the possible cost and decrease during commercialization stage, a rule of thumb is that only a significant benefit (in terms of potential market) will push the industrialization of new material (nanocarbon), even more critical in this case due to the concerns regarding health effects of nanomaterials and the absence of clear legislation regarding their use.

We believe that the use of nanocarbons for preparing advanced catalytic materials will grown in the future and become a key element of the panorama for advanced catalysts, but there are some necessary conditions to enable this possibility:

- Research in the use of nanocarbons materials has to move to applications where there is the need of significant improvement in the performances for relatively large scale catalytic processes, which justify the development of new catalysts and the investment necessary for its commercial introduction; often still research is more focused on the synthesis of nanocarbon rather than their use, and reactivity is often a side aspect rather than the core of investigation.

- It is necessary to use the peculiar properties of these catalytic materials to address novel pathways of reactions, which (i) reduce the number of steps in catalytic synthesis, the formation of byproducts and the environmental impact, (ii) enhance the selectivity and reduce the costs of downstream processing (separation, purification, environmental cleaning), (iii) reduce energy consumption and enable the use of alternative (more sustainable) raw materials. Although researchers often claim these aspects, they are not often proven and limited effort in literature can be seen to discover game-changer catalytic applications of nanocarbon materials.

- The number of novel syntheses and type of nanocarbon materials has exponentially grown and more slowly is increasing also the understanding of their characteristics, including reactivity. It is necessary to turn approach, and develop a theory of catalysis by nanocarbon materials allowing to define which type of properties are specifically requested to improve the behaviour in a specific catalytic reaction. Then synthetize the nanocarbon having these characteristics.

- It is necessary to put more attention on the reproducibility of the performances, especially at nanoscale level, in moving to large-scale applications. Still many factors are uncontrolled.

These aspects will be further commented later. 


\section{Type of nanocarbons}

Previous section remarked the need to put on more rational bases the investigation on nanocarbons for catalytic application as one of the elements to make the necessary step-change in their use and enable their large-scale use in the preparation of the next-generation catalysts. It is necessary to consider from a different perspective their characteristics, starting from the classification. It is possible to distinguish three generations of nanocarbon materials relevant for catalytic applications:

- 1'st generation: fullerene, graphene, and CNTs. Different nanocarbons with simple morphology derive from them: carbon quantum dots, nanohorn, nanofiber, nano ribbon, nanocapsulate, nanocage and other nanomorphology. These nanocarbon have a low dimensionality and morphology-defined properties.

- $2^{\text {nd }}$ generation: the electronic structure in these carbon materials is tailored by introducing heteroatoms, their physical properties are tuned by controlling the pore structures, and their chemical properties are changed by specific surface functional groups. In other words, a further level of control in the characteristics of the nanocarbon is introduced during the synthesis or by post-synthesis treatments.

- $3^{\text {rd }}$ generation: a further level of control in the properties of nanocarbons is realized by designing hybrid and/or hierarchical systems. These materials are nano-architectured, e.g. the reactivity properties depend critically on the nano-architecture not only in terms of mass transfer, the classical motivation to realize hierarchical structured catalysts. This approach introduces a new level of control in the catalytic performances.

Research on nanocarbons is decreasing from the $1^{\text {st }}$ to $3^{\text {rd }}$ generation catalysts, but is the rational development of the $3^{\text {rd }}$ generation nanocarbon-based catalysts, which may open the door to the breakthrough-type applications (mentioned in the previous section). This may be considered the actual bottleneck to move to commercial use nanocarbon-based catalysts, which alone do not justify the effort and cost to move to conceptually-new catalysts.

\section{The new scenario for chemical production}

It is necessary to shortly discuss here the new scenario for chemical production [35-38], because it is more likely that new nanocarbon-based catalysts can be introduced on novel processes rather than on established one for a number of reasons: (i) it is not necessary to switch to a new catalyst formulation, and the development of the new catalyst goes in parallel to the development of the new process; (ii) at the stage of development of a new process, using alternative raw materials for example, there is competition between different companies; a conceptually-new catalyst based on nanocarbon may be a winning element for the market; (iii) the degree of possible improvements in a novel process is typically larger than that of established processes, which have been optimized in a number of years. On the other hand, time-to-market in the field of novel sustainable processes may be often short, limiting the interest to develop new type of catalysts that require longer time for development.

The evolution of chemical production can be viewed, from an historical perspective, as the result of pushing forces due to social (market) demand, security, environment, quality of life, etc. and pulling forces due to availability of new raw materials, technology developments, etc. Due to the different dynamic of evolution of these forces, it is not present a linear evolution, but a cyclic evolution with the presence of periods of renewal, prosperity, recession and depression. There are many indications, from socio-economic to technological ones, pointing out that the chemical industry is moving to a new development cycle characterized by global structural changes in the economy with reorganisation of the energy and resource infrastructure, the switch to renewable energies and sustainable issues largely influencing the market and industrial objectives [39]. Chemical industry is at a turning edge leading to major change in its structure, with the increasing need to find new raw materials substituting fossil fuels for the production of chemicals and polymers (and energy), and new production methodologies which decouple production from the scale-economy.

Biomass as chemical feedstock, (re)use of $\mathrm{CO}_{2}$, waste valorisation, use of renewable energy, use of fossil fuels alternative to oil (actually accounting for majority of petrochemistry production), from shale gas to coal, are between the major changes in the chemical production to respond to the request of a resource and energy efficient sustainable future and to move to a low carbon economy [35-38]. Figure 1 summarizes the evolution in the scenario of raw materials from current petrochemistry to the future scenario for a sustainable and low carbon chemical production [36].

It is not the scope here to discuss in detail this changing scenario and the different reactions, which should be developed to enable this future. Various aspects have been discussed in ref.s [35-38]. However, it should be remarked that this evolution of chemical production opens new needs for catalysis, and new opportunities for the use of nanocarbons to respond to this challenge. Between the various reactions for which nanocarbons may play a key role to develop improved catalysts may be cited:

- The Fischer-Tropsch to olefin (FTO) process to convert $\mathrm{CO}_{2}$ and renewable $\mathrm{H}_{2}$ to light olefins; here the challenge is to maximize the selectivity (avoiding formation of methane and heavier products) and improve productivity as well [39].

- The development of advanced photo- and electro-catalysts for producing $\mathrm{H}_{2}$ from water using solar energy, and for devices able to convert $\mathrm{CO}_{2}$ to tailored chemicals (methanol, hydrocarbons, higher alcohols, etc.) using sunlight and water [40-44]. Nanocarbons here may play many roles: antenna centers to capture the light, systems for charge transport and separation, catalytic centers for the reaction, etc. $[29,45]$.

- The selective conversion of light alkanes associated to shale gas to produce selectively monomers for polymerization. Here, the challenge is to make a step-change (in- 

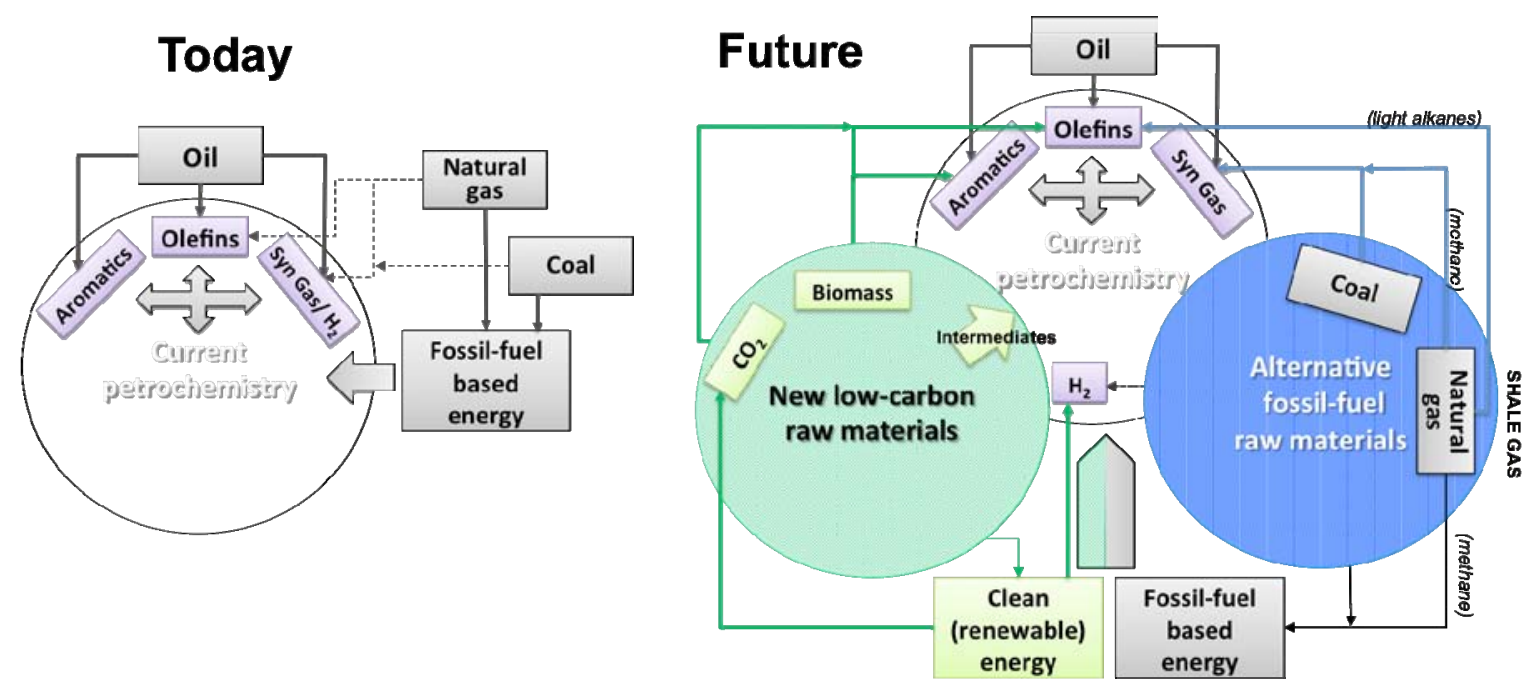

Fig. 1. Evolution in the scenario of raw materials from current petrochemistry to the future scenario for a sustainable and low carbon chemical production. Adapted from ref. [36].

crease of $10 \%-20 \%$ in selectivity at high conversion) in the catalytic performances with respect to current state-of-the-art catalysts, based on mixed metal oxides [46]. Nanocarbons show rather interesting properties for this type of reactions [1].

- The development of advanced catalytic electrodes [19,20] for various reactions of energy storage and conversion, for example the electrocatalytic conversion of $\mathrm{CO}_{2}$ to higher alcohols [44], but also for the development of advanced bio-electrodes (made by supporting enzymes over nanocarbon based electrodes [47]), one of the frontier research for exploring new sustainable catalytic routes for using renewable resources [48].

- The use of nanocarbons to develop improved catalysts to enable the production of cleaner reactants, such as $\mathrm{H}_{2} \mathrm{O}_{2}$ $[49,50]$.

- The use of nanocarbons to develop new routes for the catalytic conversion of biomass, for example by hydrogenation of cellulose [51] or to produce biofuels using heterogeneous catalysts [52].

- The use of nanocarbons to develop new type of catalytic membranes, for example based on aligned CNTs, which open new perspectives to develop novel catalytic materials [53] and energy-saving chemical processes (for example, nanodiamond immobilized membranes for enhanced desalination via membrane distillation [54]).

Above list does not certainly cover all the field of use of nanocarbons to develop the next-generation catalysts for a sustainable development, but gives the feeling of the broad range of possible applications. We have not mentioned in the list the raising area of the use of nanocarbon materials to develop metal-free electrodes for oxygen reduction reaction (ORR) in fuel cells [17,55-58]. This is an important development, but does not open new paths itself, because electrocatalysts based on noble or other metals already exist for this reaction and still the properties of these metal-free nanocarbon-based electrodes are lower under proper testing condi- tions (e.g. high current density). However, moving from fuel cells to electrocatalytic reactions these metal-free nanocarbon electrodes open new perspectives, for example for the selective activation of oxygen in selective oxidation reactions or even to completely-new sustainable reactions.

Synthesis of ammonia, although discovered from over a century, is still a great challenge and the development of catalysts able to activate $\mathrm{N}_{2}$ and form ammonia in very mild conditions (e.g. not at very high pressure) is a "holy grain". Understanding the mechanism of $\mathrm{O}_{2}$ activation during ORR reaction [17] could lead to the possibility of applying an analogous mechanism to activate $\mathrm{N}_{2}$, which, in the presence of suitable co-catalyst functions for hydrogen activation and transfer, allows to form $\mathrm{NH}_{3}$ under very mild conditions, bypassing current thermodynamic limitations in this reaction. However, there are still no studies in this challenging direction.

Finally, it should be mentioned how nanocarbon materials are increasingly investigated and deployed in technologies and devices for sustainable energy conversion and storage: solar cells, water splitting, supercapacitors, lithium ion batteries, fuel cells $[29,45]$.

\section{Potential advantages in using nanocarbon materials for advanced catalysts}

There is a number of potential advantages given by the use of nanocarbon materials to develop advanced catalysts, in comparison to the use of AC, other type of carbon materials such carbon gels [59] and aerogels [60], or different nanostructured catalytic materials such as mixed oxides [61]. Some of these aspects are summarized in Table 1, together with some of the key aspects, which need to be further investigated. There are thus many motivations for their use. It may be remarked that often carbon materials have been considered an "inert" support, in comparison to mixed oxides, for example. As discussed also later, it is evident that carbon materials, and particularly nanocarbons, are instead showing a rich functional 
surface activity, with different type of surface groups (depending on the preparation and functionalization of nanocarbon) showing itself a rich catalytic chemistry (metal-free carbon catalysts [55,58,62-65]).

Although knowledge are growing, it is still missing a complete picture of how put in relation the presence of these surface functional groups to the characteristic nano-dimension and nano-architecture of the nanocarbon. Stability of many of these functional groups is also still an issue in comparison with "conventional" catalysts, as well as the possibility to maximize their concentration to improve the catalyst productivity.

\section{Nano-engineering of nanocarbon catalytic materials}

Nano-engineering of the catalytic sites defines the possibil- ity to design the optimal spatial arrangement at nano-scale level of the multiple functional centers necessary in a catalytic site for complex multistep catalytic reactions (the challenge to move to a more sustainable chemical production [46]) as well as to optimize the paths in the solid for a vectorial-type access of reactants and fast back transport of the products of reaction, eventually also with gate-type centers to control access and back-diffusion. This is the actual frontier of research in catalytic (next-generation) materials and nanocarbons are between the most advanced materials to move in this direction.

However, this challenge requires the ability to:

(1) Determine first the optimal 3D-configurations for multifunctional active centers capable to perform the target reactions (notwithstanding the impressive progresses in theoretical modelling catalytic reactions and

Table 1

Potential advantages given by the use of nanocarbon materials to develop advanced catalysts, in comparison to the use of other type of carbon materials or other nanostructured catalytic materials such as mixed oxides.

\begin{tabular}{ll}
\hline Advantages & Comments and aspects to be understood \\
\hline Better pore structure & Nanocarbons such as CNTs have a surface area mainly associated to the external geometrical area (for SWCNT \\
& and DWCNT inner surface may also contribute significantly). Mesoporosity is predominantly associated to the \\
& voids created from the CNT network. Microporosity, leading often to diffusional problems, a lowering of selec- \\
& tivity and incomplete utilization of the supported active metal particles, is often negligible [66]. Micro-porosity
\end{tabular}

More uniform characteristics Carbons deriving from natural sources (nutshells, peat, etc.) show often properties depending largely on the is also often a main issue in high-surface-area metal-oxide catalysts. type of impurities present in the starting material. Nanocarbons allow obtaining better uniformity in terms of size distribution, graphitization degree and purity, although improvements are still necessary. For example, controlling the chirality and diameter of single-walled CNTs is still a challenge, as well as the control of the uniformity in the electronic properties (metallic, semi-metallic or semi-conductor character). Purity and more defined structural uniformity are both important aspects in catalytic reactions to minimize side reactions. In mixed-oxide uniform composition at the nanoscale level is also often still a great issue.

Reduced number of defects and impurities

Nanocarbons (CNTs, graphene and others with well-defined nano-structure) have defect sites incorporated in $s p^{2}$ bonded carbon network, while ACs with disordered structure have a huge number of different type of defective sites (AC is a complex structure composed primarily of graphitic-like sheets - basal planes-joined by random cross-linking resulting in a highly porous structure with a myriad of cracks and crevices). In nanocarbons it is possible to have a defined and controlled type of defects. However, the understanding and control of this aspect, which plays a key role in determining the catalytic performances, is still largely a challenge. In nano-structured metal-oxide catalysts, as well as often in some zeolites and mesoporous materials, defect chemistry also plays a critical role in various reactions, but still largely not well understood.

Enhanced oxidative resistance for chemical reactions Nanocarbons such as CNTs and some others (but not all type of nanocarbons) show often an enhanced oxidative resistance to oxidation [67] and in general chemical corrosion with respect to AC or other type of carbon materials. However, the control of defect characteristics plays an important role (still to be better understood), because the mechanism of carbon combustion starts with oxygen dissociation on active sites related to defects and functional groups at the edges of the basal plane [68]. For high temperature reactions or in electrocatalysis in the presence of oxygen this enhanced resistance to oxidation is often critical for stability, although not often verified in long-term runs [68,69]. It is also critical for safety in industrial reactors, to avoid runaway. In hybrid nanocarbon materials with metal oxide nanoparticles, the latter plays a special role, because the oxidation stability results inversely proportional to the metal oxides reducibility, i.e. the ability to create oxygen vacancies [70].

Better electron and heat transport Nanocarbons allow in general a faster and more efficient electron and heat transport with respect to AC [71] and largely greater with respect to metal-oxides. The electron and heat transport properties depend greatly on the specific characteristics of carbon material. Carbon black, one of the most conductive conventional carbon materials, has a volume resistivity about $10 \Omega \mathrm{cm}$, while CNTs a volume resistivity in the $10^{-2}-10^{-3} \Omega \mathrm{cm}$ typical range [72]. However, the control of these properties, particularly in $2^{\text {nd }}$ and $3^{\text {rd }}$ generation nanocarbons, and of their uniformity at a nano-scale level, is still largely a challenge. The characterization of interface between nanocarbons and/or with other interacting nanostructures, and the role of this interface in determining the global electron, charge and heat transport properties is still largely unclear.

Better mobility of surface species and electronic coupling between active sites These are aspects very few investigated, but that we anticipate may play an important role in determining the catalytic performances. It is often necessary to spatially separate the active centres necessary in a complex multi-step reaction mechanism. A good mobility of surface species between these sites and/or electronic coupling between the active sites is an important element for catalytic behaviour. Typically, this is relevant at high conversion rates and surface coverage by adspecies, and for this reason not recognized in spectroscopic investigations on the reaction mechanism. 
Table 1 (continued)

Advantages

of adsorption

Specific surface reactivity associated to bond strains due to curvature

From isolating to metallic properties through semi-conducting behaviour

Specific active sites

Nano-engineering of catalytic sites
Comments and aspects to be understood

It is growing the understanding of how the mechanism of adsorption of reacting molecules influences the reactivity and selectivity. For example, the planar adsorption of an alkylaromatic through the $\pi$-bonds of the aromatic ring gives a different type of products with respect to the vertical interaction through the alkyl group. The presence of sites near the catalytic center, which may induce a different mechanism of adsorption or the stabilization of some of the reaction intermediates, has thus a large influence on the catalytic reactivity, which is starting to be understood. Nanocarbons, with the presence of graphitic zones and the different type of adsorption mechanism with respect to oxides or metal particles, offer great possibilities to control and improve reactivity and selectivity. However, knowledge in this direction are still quite limited.

Due to the possibility of different sp states for carbon $\left(s p^{1}, s p^{2}, s p^{3}\right)$ and the formation of different type of rings, carbon chemistry is very rich, going from a planar situation (graphene) to tubular configuration (nanotubes) and ball-shape structure (fullerene), but a large variety of intermediate situation exist between these limit configurations, for example in nano-onion and nano-diamond. This will generate many different surface sites, which together with the presence of defects and strains in C-C bonds (associated to curvature) lead to a different surface reactivity. Although studies in this direction are still quite limited, evidences are accumulating on how these sites may play a critical role in some reactions, for example the old synthesis of phosgene.

Nanocarbon materials possess the unique property (for a single series of materials with a single element-carbon, in this case) to have electronic properties, depending on the nanostructure and preparation, which can go from non-metallic to metallic properties, and in some case also a semi-conducting behaviour. In some case, this could be an issue (obtaining CNTs carpets with all the CNT having the same electronic properties is still a major issue), but in general this characteristic offers a rich range of possibilities to develop advanced catalysts. However, studies in this direction are quite limited.

The catalytic reactivity of nanocarbon is associate to the presence of different type of oxygen or nitrogen functionalities, as well as defect sites, introduced during preparation, doping or post-synthesis method. Of the many possible active sites, not all are stable and preferentially present on the accessible surface during the catalytic reaction. The location of these sites is an important element for the catalytic reactivity as well as the presence of contiguous sites (for example, continuous carbonyl sites). However, the relation with the nanostructure and the role in the reaction mechanism is often still not well understood, or a matter of debate. The synergy of these sites with surface impurities (metal ions or other species) deriving from the preparation or specifically introduced, is still largely unclear. The role of defects and perimetral edges (for example, in graphene sheets) in generating active centers or directly in the reaction mechanism is largely unclear, as well as how these sites can be controlled during preparation.

The progress in the controlled synthesis of nano-architectured carbon materials is more advanced with respect to other catalytic materials. Although still various issues are present in controlling the architecture at the nano-scale, the nature of functional sites and their localization at specific positions (site-controlled functionalization), nanocarbons are between the more promising systems to move to nano-engineering of catalytic sites, the challenge to develop next-generation catalytic materials. characterization of the reaction mechanism, this is still a challenge);

(2) Then to synthetize these catalytic nano-objects containing the necessary functionalities to close the catalytic cycle;

(3) Finally assemble them in an organized 3D overstructure, which allows the controlled access to the active centers of the reactants and back-transport of the products, avoiding at the same time parallel or consecutive side reactions.

Although some elements for this nano-engineering are emerging in literature, still a large research effort is necessary to move along this direction in a more systematic way. The first challenge facing nanoscience is to develop efficient and robust synthetic mechanisms of assembling nano-components that not only use the properties of individual particles, but also their functional interaction:

- To guarantee an optimized charge, mass and heat transport in the designed devices;

- To vectorialize this transport along defined paths (to minimize side reactions);

- To introduce gate functionalities which regulate transport (similar to what present in enzymes) [20].
In a general term, this is the concept of hierarchically-organized materials, but it is evident how the concept presented above goes far beyond the concept of the hierarchical materials actually investigated. Engineering or architecturing in nanoscale requires the capacity in carbon materials of

(i) Manipulating the chemical composition and nanostructure in a desired way; this is still a challenge, notwithstanding the progresses in the synthesis of nanocarbons;

(ii) Hierarchical ordering at the necessary nano-dimensional level. There are growing knowledge on these aspects, although still a better control is necessary; for example, how control the growth rate of CNTs in order to tailor their length;

(iii) Integrating nano-objects of the same or different nature not using self-assembly methods (a popular research area), but using tailored methodologies capable to realize an optimal molecular transport through broad "highways" leading to specific active centers; there is a large synthetic effort to progress in this direction;

(iv) Realizing the ordered nano-hybrid catalytic materials for the target reaction, but at the same time inducing the many other features (from mechanical strength to 
stability and macro-shape for use in industrial-size reactors) necessary for their industrial exploitation; some progresses exist in this direction, but still a synthetic effort is necessary.

Notwithstanding research on nanocarbon have been largely focused on synthesis procedures, it is necessary a further effort in this direction, but driven from a more rational analysis of the characteristics necessary to develop next-generation catalysts, and from the ability of a better control at the nano-scale and at the macro-shape levels the composition, presence of active centers, overstructure and architecture.

Carbon hierarchy is one of the actively investigated areas in application of nanocarbons, although more for energy applications than for catalytic one. This sector is mainly focused on the investigation of combinations of two nanocarbon (graphene, carbon nanotubes or nanofibers, nanodiamond, nano-porous carbons or polymers) building blocks, to induce superior properties with respect to those of the individual elements [3] or the preparation of a bi-modal pore distribution combining the microporous characteristics of nanoscale carbon elements with the mesoporous characteristics deriving from the arrangement of these building blocks [73]. Examples are the use in sequence of hard- and soft-template methods $[74,75]$ or the catalytic grown of CNTs during high temperature graphitization of spherical carbon nanostructures [76]. There are many more examples in this exponentially growing scientific area, from dendritic structures of CNTs/CNFs [77] to nano-in-nano design [78], but it is not the aim an analysis of the different nanostructured proposed in literature. It is worth to note, however, that these hierarchical carbon materials may show advantages over "conventional" carbon materials in terms of mass transport limitations, but they are still far from the advanced concept of tailored catalytic solid space at the nanoscale-level outlined above. They are a necessary step to move in this direction, but a further step-forward in research approach is necessary.

\section{Defect-related catalytic reactivity}

We have remarked in the previous sections how defects in nanocarbons may have an important role in determining their surface reactivity. In general, nanocarbons have a higher number of defects with respect to other type of catalysts such as oxides [61], because a high defect concentration in the latter leads to a structural rearrangement, while the graphitic network is able to accommodate defects through local rather than extended changes. For example, an isolated pentagon turns a single-wall CNT into a sharp cone and a heptagon into a horn [79]. One of the most common defects is pair of pentagon-heptagon (5/7), which presence determines a changes in the chirality of single-wall CNTs [79]. The formation energies of a 5/7 defect site in single-wall CNTs is typically quite low ranging between 2 and $4 \mathrm{eV}$. Defect healing, e.g. the removal of defect during growth, determines the type of chirality in the growth of single-wall CNT [80]. Hembram et al. [81] proposed a generalized model for the grown of defective multi-wall CNTs.

There are thus tools for nano-engineering of CNTs in terms of defects (type and concentration), and it is known that defects in nanocarbons play a relevant role in the catalytic reactivity [82]. Tessonier et al. [83], for example, showed that defects in carbon nanotubes determined a key role for their functionalization and the development of catalysts for biomass conversion. The CNT characteristics (diameter, chirality, number and type of defects, functionalization, etc.) determine the production of reactive oxygen species during irradiation and this influences the photocatalytic behaviour [84]. Similarly, highly defective CNTs show high photocatalytic activity [85]. These are some examples of an emerging literature on these aspects, but on the other hand it has to remark how often the missing understanding of these aspects leads to contrasting or unclear results in literature. The introduction of defects in nanocarbon modifies several properties, from the surface reactivity to the surface mobility of adspecies and the electron conductivity, the surface hydrophilicity, etc. It is necessary to investigate and rationalize all these aspects to determine the relation with the catalytic behaviour, and/or the relative contribution to the catalytic performances [86]. This explains why this topic still remains a challenge.

Defects play also an important role to stabilize supported metal nanoparticles. Although this is recognized as an important factor to understand the catalytic chemistry and stability of supported metal particles, there are still limited studies analysing this aspect and the relation with the characteristics of nanocarbons. Pham-Huu and coworkers [87] showed the high reactivity of the graphene border and basal plane to anchor metal nanoparticles. This interaction is strong enough to prevent metal nanoparticles sintering at high thermal annealing temperature $\left(600-700^{\circ} \mathrm{C}\right)$. The diffusion and coalesce of metal nanoparticles along the defects determines a change in their shape, from nearly spherical Pt nanoparticles with average sizes of $2 \mathrm{~nm}$ located preferentially at the support topographical defects (e.g., steps and edges) to more facets nanoparticles (of average size about $5 \mathrm{~nm}$ ) showing larger number of Pt atoms in contact with the one-layer graphene support.

There are thus many aspects related to the role of defects in influencing the catalytic behaviour of nanocarbons, which are beginning to be under understood. However, a more systematic understanding will turn from the observation of the effects to the possibility to use in a rational planning of advanced catalysts based on nanocarbons.

\section{Conclusions}

Nanocarbon will play a key role in many of the critical and enabling routes for a resource and energy-efficient future, but it is necessary at step forward in approaching their use as advanced and conceptually-new catalytic materials, and at the same time in using the growing knowledge on their surface chemistry to approach the still many challenging reactions facing industrial chemistry. This essay has remarked some of the possibilities, but also the many open problems on these nano-materials. As remarked, the aim is not a systematic analysis, but to give a glimpse on the future directions of nanocarbon catalytic materials, as an introduction of the specific issue of 
"Chinese Journal of Catalysis" dedicated to this topic. Various aspects remarked in this essay are investigated in this special issue providing an updated state-of-the-art on new directions of research in this topic.

This special issue also further demonstrates how this scientific area is becoming an increasingly relevant and important autonomous subject in heterogeneous catalysis, and how nanocarbons offer an unmatched possibility for designing advanced catalysts. We thus conclude with the indication that nanocarbon-based catalysts are one of the most promising directions to develop next-generation catalysts, but turning this expectation into a reality needs not only an intensified R\&D, but especially to change the perspective in investigating these materials. This essay has outlined some of these necessary new perspectives, but only when companies will identify this scientific area as a key element to realize the new chemical processes for a sustainable and competitive production, the synergetic interaction with the scientific community will boost to overcome the gap for innovation still present in this area.

\section{References}

[1] Su D S, Perathoner S, Centi G. Chem Rev, 2013, 113: 5782

[2] Mleczko L, Lolli G. Angew Chem Int Ed, 2013, 52: 9372

[3] Vilatela J J, Eder D. ChemSusChem, 2012, 5: 456

[4] Su C L, Loh K P. Acc Chem Res, 2013, 46: 2275

[5] Dreyer D R, Bielawski C W. Chem Sci, 2011, 2: 1233

[6] Jüntgen H. Fuel, 1986, 65: 1436

[7] Rodríguez-Reinoso F. Carbon, 1998, 36: 159

[8] Reimerink W M T M. Stud Surf Sci Catal, 1999, 120A: 751

[9] Dreyer D R, Jia H P, Bielawski C W. Angew Chem Int Ed, 2010, 49: 6813

[10] Schaetz A, Zeltner M, Stark W J. ACS Catal, 2012, 2: 1267

[11] Su C L, Acik M, Takai K, Lu J, Hao S J, Zheng Y, Wu P P, Bao Q L, Enoki T, Chabal Y J, Loh K P. Nature Commun, 2012, 3:1298

[12] Centi G, Perathoner S. Catal Today, 2010, 150: 151

[13] Centi G, Perathoner S. ChemSusChem, 2011, 4: 913

[14] Bitter J H.J Mater Chem, 2010, 20: 7312

[15] Su D S, Schlögl R. ChemSusChem, 2010, 3: 136

[16] Umeyama T, Imahori H.J Phys Chem C, 2013, 117: 3195

[17] Wang D W, Su D S. Energy Environ Sci, 2014, 7: 576

[18] Sun H Q, Wang S B. Energy Fuels, 2014, 28: 22

[19] Centi G, Perathoner S. Eur J Inorg Chem, 2009, (26): 3851

[20] Centi G, Perathoner S. Coord Chem Rev, 2011, 255: 1480

[21] Wang H L, Dai H J. Chem Soc Rev, 2013, 42: 3088

[22] Guerra J, Herrero M A. Nanoscale, 2010, 2: 1390
[23] Conley M P, Coperet C, Thieuleux C. ACS Catal, 2014, 4: 1458

[24] Li H Q Song S I, Song G Y, Kim I. J Nanosci Nanotechnol, 2014, 14: 1425

[25] Calvaresi M, Zerbetto F. Acc Chem Res, 2013, 46: 2454

[26] Yu G H, Xie X, Pan L J, Bao Z A, Cui Y. Nano Energy, 2013, 2: 213

[27] Liang Y Y, Li Y G, Wang H L, Dai H J. J Am Chem Soc, 2013, 135: 2013

[28] Centi G, Perathoner S. In: Nanocarbon-Inorganic Hybrids, Ch. 17. Berlin (Germany): De Gruyter, 2014. In press

[29] Su D S, Centi G. Nanoporous Materials for Energy and the Environment. Singapore: Pan Stansford Pub, 2012.173

[30] Mao S, Lu G H, Chen J H. J Mater Chem A, 2014, 2: 5573

[31] Ito O, D'Souza F. ECS J Solid State Science Technol, 2013, 2: M3063

[32] Dirian K, Herranz M A, Katsukis G, Malig J, Rodriguez-Perez L, Romero-Nieto C, Strauss V, Martin N, Guldi D M. Chem Sci, 2013, 4: 4335

[33] Wang Q H, Bellisario D O, Drahushuk L W, Jain R M, Kruss S, Landry M P, Mahajan S G, Shimizu S F E, Ulissi Z W, Strano M S. Chem Mater, 2014, 26: 172

[34] Patel V. Global Carbon Nanotubes Market-Industry Beckons. Nanowerk Spotlight, 2013

[35] Perathoner S, Centi G. ChemSusChem, 2014, DOI: 10.1002/ cssc.201300926

[36] Lanzafame P, Centi G, Perathoner S. Chem Soc Rev, 2014, DOI: 10.1039/C3CS60396B

[37] Lanzafame P, Centi G, Perathoner S. Catal Today, 2014, DOI: 10.1016/j.cattod.2014.03.022

[38] Perathoner S, Centi G. J Chinese Chem Soc, 2014, DOI: 10.1002/ jccs. 201400080

[39] Centi G, Iaquaniello G, Perathoner S. ChemSusChem, 2011, 4: 1265

[40] Bensaid S, Centi G, Garrone E, Perathoner S, Saracco G. ChemSusChem, 2012, 5: 500

[41] Genovese C, Ampelli C, Perathoner S, Centi G. J Energy Chem, 2013, 22: 202

[42] Ampelli C, Passalacqua R, Genovese C, Perathoner S, Centi G. Chem Eng Trans, 2011, 25: 683

[43] Ampelli C, Passalacqua R, Perathoner S, Centi G. Chem Eng Trans, 2009, 17: 1011

[44] Genovese C, Ampelli C, Perathoner S, Centi G. J Catal, 2013, 308: 237

[45] Su D S, Centi G.J Energy Chem, 2013, 22:151

[46] Cavani F, Centi G, Perathoner S, Trifirò F. Sustainable Industrial Chemistry: Principles, Tools and Industrial Examples. Germany: Wiley-VCH, 2009

[47] Miyake T, Yoshino S, Yamada T, Hata K, Nishizawa M. J Am Chem Soc, 2011, 133: 5129

[48] Centi G, van Santen R A. Catalysis for Renewables. Germany:

\section{Graphical Abstract}

\section{Chin. J. Catal., 2014, 35: 783-791 doi: 10.1016/S1872-2067(14)60139-X}

\section{Carbon-based catalysts: Opening new scenario to develop next-generation nano-engineered catalytic materials}

Claudio Ampelli, Siglinda Perathoner*, Gabriele Centi

University of Messina, INSTM/CASPE and ERIC aisbl, Italy

This essay analyses some of the recent development in nanocarbons, with reference to their use as advanced catalytic materials. Carbon nano-engineered materials represent a new class of catalysts.

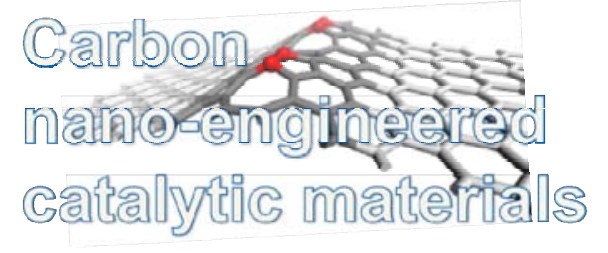


Wiley-VCH, 2007

[49] Arrigo R, Schuster M E, Abate S, Wrabetz S, Amakawa K, Teschner D, Freni M, Centi G, Perathoner S, Hävecker M, Schlögl R. ChemSusChem, 2014, 7: 179

[50] Abate S, Freni M, Arrigo R, Schuster M E, Perathoner S, Centi G. ChemCatChem, 2013, 5: 1899

[51] Van de Vyver S, Geboers J, Schutyser W, Dusselier M, Eloy P, Dornez E, Seo J W, Courtin C M, Gaigneaux E M, Jacobs P A, Sels B F. ChemSusChem, 2012, 5: 1549

[52] Tessonnier J P, Villa A, Majoulet O, Su D S, Schlögl R. Angew Chem Int Ed, 2009, 48: 6543

[53] Rios G, Centi G, Kanellopoulos K. Nanoporous materials for energy and the environment. Singapore: Pan Stanford Pub, 2012

[54] Bhadra M, Roy S, Mitra S. Desalination, 2014, 341: 115

[55] Daems N, Sheng X, Vankelecom I F J, Pescarmona P P. J Mater Chem A, 2014, 2: 4085

[56] Wu G, Zelenay P. Acc Chem Res, 2013, 46: 1878

[57] Yang Z, Nie H G, Chen X A, Chen X H, Huang S M. J Power Sources, 2013, 236: 238

[58] Zheng Y, Jiao Y, Jaroniec M, Jin Y G, Qiao S Z. Small, 2012, 8: 3550

[59] Maldonado-Hodar F J. Catal Today, 2013, 218

[60] White R J, Brun N, Budarin V L, Clark J H, Titirici M M. ChemSusChem, 2014, 7: 670

[61] Centi G, Perathoner S. In: Comprehensive Inorganic Chemistry II, Section 7.18 "Mixed-Metal Oxides", 2014, DOI: 10.1016/B978-008-097774-4.00718-X

[62] Su D S, Zhang J, Frank B, Thomas A, Wang X C, Paraknowitsch J, Schlögl R. ChemSusChem, 2010, 3:169

[63] Sun X Y, Wang R, Su D S. Chin J Catal (孙晓岩, 王锐, 苏党生. 催化 学报), 2013, 34: 508

[64] Yu D S, Nagelli E, Du F, Dai L M. J Phys Chem Lett, 2010, 1: 2165

[65] Zhang M, Dai L M. Nano Energy, 2012, 1: 514

[66] Tessonnier J P, Su D S. ChemSusChem, 2011, 4: 824

[67] Serp P, Corrias M, Kalck P. Appl Catal A, 2003, 253: 337

[68] Frank B, Rinaldi A, Blume R, Schlögl R, Su D S. Chem Mater, 2010,
22: 4462

[69] Villa A, Wang D, Dimitratos N, Su D S, Trevisan V, Prati L. Catal Today, 2010, 150: 8

[70] Aksel S, Eder D.J Mater Chem, 2010, 20: 9149

[71] Bandaru P R. J Nanosci Nanotechnol, 2007, 7: 1239

[72] Wen M, Sun X J, Su L, Shen J B, Li J, Guo S Y. Polymer, 2012, 53: 1602

[73] Lei Y, Yeong K S, Thong J T L, Chim W K. Chem Mater, 2004, 16: 2757

[74] Wang D W, Li F, Liu M, Lu G Q, Cheng H M. Angew Chem Int Ed, 2008, 47: 373

[75] Zeng Q C, Wu D C, Zou C, Xu F, Fu R W, Li Z H, Liang Y R, Su D S. Chem Commun, 2010, 46: 5927

[76] Zhang J, Wang R, Liu E Z, Gao X F, Sun Z H, Xiao F S, Girgsdies F, Su D S. Angew Chem Int Ed, 2012, 51: 7581

[77] Ma H L, Su D S, Klein-Hoffmann A, Jin G Q, Guo X Y. Carbon, 2006, 44: 2254

[78] Zhang J, Hu Y S, Tessonnier J P, Weinberg G, Maier J, Schlögl R, Su D S. Adv Mater, 2008, 20: 1450

[79] Yuan Q H, Xu Z P, Yakobson B I, Ding F. Phys Rev Lett, 2012, 108: $245505 / 1$

[80] Kim J, Page A J, Irle S, Morokuma K. J Am Chem Soc, 2012, 134: 9311

[81] Hembram K P S S, Rao G M. Mater Lett, 2012, 72: 68

[82] Carlsson J M, Scheffler M. Phys Rev Lett, 2006, 96: 046 806/1

[83] Tessonnier J P, Villa A, Majoulet O, Su D S, Schlögl R. Angew Chem Int $E d, 2009,48: 6543$

[84] Chen C Y, Jafvert C T. Environ Science Technol, 2010, 44: 6674

[85] Luo Y S, Heng Y F, Dai X J, Chen W Q, Li J L. J Solid State Chem, 2009, 182: 2521

[86] Centi G, Gangeri M, Fiorello M, Perathoner S, Amadou J, Bégin D, Ledoux M J, Pham-Huu C, Schuster M E, Su D S, Tessonnier J-P, Schlögl R. Catal Today, 2009, 147: 287

[87] Moldovan M S, Bulou H, Dappe Y J, Janowska I, Bégin D, Pham-Huu C, Ersen O.J Phys Chem C, 2012, 116: 9274 